\title{
Ultrasound guidance for femoral venous access in electrophysiology procedures-systematic review and meta-analysis
}

\author{
Péter Kupó ${ }^{1,2}$ (1) $\cdot$ Róbert Pap $^{2} \cdot$ László Sághy $^{2} \cdot$ Dalma Tényi $^{3} \cdot$ Alexandra Bálint $^{1} \cdot$ Dorottya Debreceni $^{1}$. \\ Indranill Basu-Ray ${ }^{4,5} \cdot$ András Komócsi $^{1}$
}

Received: 1 July 2019 / Accepted: 2 December 2019 / Published online: 10 December 2019

(C) The Author(s) 2019

\begin{abstract}
Purpose The most common complications of electrophysiology (EP) procedures are related to vascular access. Our study aims to conduct a meta-analysis comparing ultrasound (US)-guided vs. palpation-based technique for femoral venous access in EP procedures.

Methods Electronic databases were searched and systematically reviewed for studies comparing femoral vein puncture with/ without US in EP procedures. The primary outcome was the rate of major vascular complications; secondary outcomes were minor vascular complications, inadvertent artery puncture, postprocedural groin pain, and puncture time. Predefined subgroup analysis was conducted separately for patients undergoing pulmonary vein isolation procedure (PVI). A random-effects model was used to derive risk ratios (RR) with $95 \%$ confidence interval (CI).

Results Nine studies involving 8232 patients met our inclusion criteria. Compared with the standard technique, the use of US reduced major vascular complications (from 2.01 to $0.71 \%, p<0.0001$ ). The rate of minor vascular complications $(\mathrm{RR}=0.30$, $95 \% \mathrm{CI}, 0.14-0.62, p=0.001)$ and inadvertent artery puncture were lower with US-guided puncture $(\mathrm{RR}=0.31,95 \% \mathrm{CI}, 0.17-$ $0.58, p=0.0003$ ). Puncture time was shorter (mean difference $=-92.1 \mathrm{~s}, 95 \% \mathrm{CI},-142.12--42.07 \mathrm{~s}, p=0.0003$ ) and postprocedural groin pain was less frequent $(\mathrm{RR}=0.57,95 \% \mathrm{CI}, 0.41-0.79, p=0.0008)$ in the US group. Subgroup analysis of patients undergoing PVI also showed significant reduction of major vascular complications $(\mathrm{RR}=0.27,95 \% \mathrm{CI}, 0.12-0.64$, $p=0.003)$ and inadvertent artery puncture $(\mathrm{RR}=0.35,95 \% \mathrm{CI}, 0.21-0.59, p<0.0001)$.

Conclusion Real-time US-guidance of femoral vein puncture in EP procedures is beneficial: it reduces major and minor vascular complications, inadvertent artery puncture, postprocedural groin pain, and puncture time.
\end{abstract}

Keywords Ultrasound-guided puncture - Electrophysiology procedures · Vascular access · Pulmonary vein isolation . Complications

\section{Background}

The most common complications of electrophysiology (EP) procedures are related to the vascular access. These may interfere with the quality of life of the patients and often prolong hospitalization $[1,2]$. The rate of vascular access-related complications varies depending on the definition and the type of

Péter Kupó

peter.kupo@gmail.com

1 Heart Institute, Medical School, University of Pécs, Ifjúság útja 13, Pécs H-7624, Hungary

2 Second Department of Internal Medicine and Cardiology Centre, Medical School, University of Szeged, Szeged, Hungary the procedure. Atrial fibrillation (AF) ablation carries higher risk of vascular access complications compared with other EP procedures [1]. This may be explained by the combination of uninterrupted oral anticoagulation and intraprocedural systemic anticoagulation to reduce the risk of thromboembolic complications, in addition to multiple large-bore access sites for the procedure compared with most EP procedures. This

3 Department of Neurology, Medical School, University of Pécs, Pécs, Hungary

4 St. Francis Hospital, Memphis, TN, USA

5 All India Institute of Medical Sciences, Virbhadra Marg, Rishikesh, Uttarakhand, India 
exposes patients undergoing AF ablation to a higher risk of bleeding complications, ranging from 1 to $13 \%$ depending on the cohort [1, 3-6].

Supplementing the traditional anatomy landmark-based vascular puncture, an ultrasound (US) guidance offers potential benefits including prevention of vascular access-related complications. Using an US-gel-filled sterile sleeve covered vascular probe connected to a portable ultrasonograph allows direct and real-time visualization of the inguinal region. US may clarify the anatomy of the femoral vessels and the surrounding structures and identify variations that may interfere with the success of the puncture (Fig. 1). In addition, placing the probe perpendicular over the inguinal region and the femoral vein, it is possible to follow the needle during the puncture to guide and correct its course [7]. US-guided femoral puncture has a short learning curve and does not interfere with the normal workflow of EP procedures [7]. Earlier studies reported a lower rate of inadvertent arterial puncture, a higher rate of first-pass success, and a decreased risk of complications associated with the use of US [8-10].

A previous meta-analysis of observational trials showed a $60 \%$ and $66 \%$ reduction in major and minor vascular complications using US guidance for femoral vein access in EP procedures [11]. Since this study, further important dataincluding a randomized controlled trial—-have been published comparing US-guided vs. standard technique [12].

Therefore, in the present study, we aimed to extend the earlier analyses in order to better characterize the impact of US-guidance at cannulation of the femoral vein during EP procedures.

\section{Methods}

\subsection{Search strategy}

Electronic databases (Medline, Excerpta Medica Database (EMBASE), Cochrane Register of Controlled Trials
(CENTRAL), and Scopus) were searched for relevant articles published between January 2000 and April 2019 using a search strategy that combined text word and MeSH heading. The search string was "vascular" and "ultrasound" or "ultrasonography" and "electrophysiology or electrophysiological" or "catheter ablation." No language restriction was used. Furthermore, we extended the search with the reference lists of the relevant studies and reviews, editorials, letters, and also relevant abstracts. We performed the analyses according to the PRISMA guideline [13].

\subsection{Data abstraction and statistical analysis}

Both randomized controlled and observational trialsregardless of their prospective/retrospective designcomparing real-time US-guided to conventional, anatomical landmark and palpation-guided technique for femoral vein puncture in EP procedures were identified. Selection and data abstraction were done independently by two reviewers (P.K. and A.K.). Disagreements were resolved by consensus.

The meta-analysis was conducted by using Review Manager (RevMan) Version 5.3 software (Cochrane Collaboration, London, UK). A random-effects model was used to derive risk ratios (RR) with $95 \%$ confidence interval (CI) on dichotomous outcomes and mean difference on continuous data. Heterogeneity was tested with a chi square heterogeneity statistic for which a $p$ value $<0.2$ was considered potentially heterogeneous. Consistency was assessed by the $\mathrm{I}^{2}$ statistic, which describes the percentage of total variation across studies that is due to heterogeneity rather than due to chance. Inconsistency was described as low, moderate, and high, based on $\mathrm{I}^{2}$ values of 25,50 , and $75 \%$, respectively.

The primary outcome was the presence of major vascular complications (groin hematoma, arteriovenous fistula, and pseudoaneurysm). Hematoma was considered to be a major vascular complication if it met type 2 or higher Bleeding
Fig. 1 Illustrative examples of two-dimensional ultrasound images of the femoral vessels with expected (Panel a) and unexpected (Panel b) localization. CFA common femoral artery, CFV common femoral vein

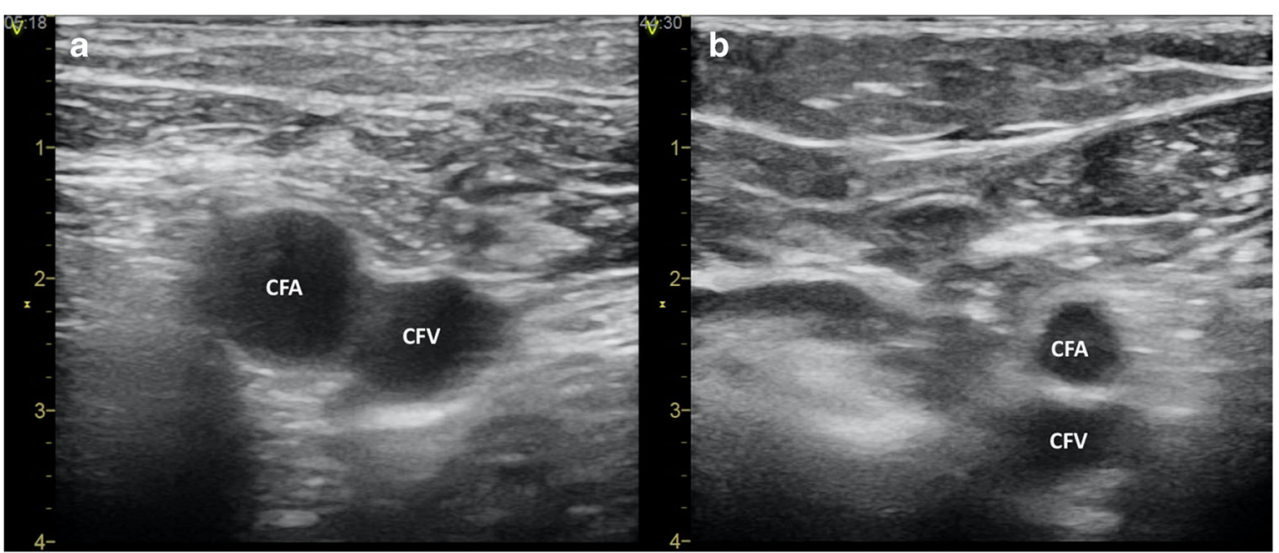




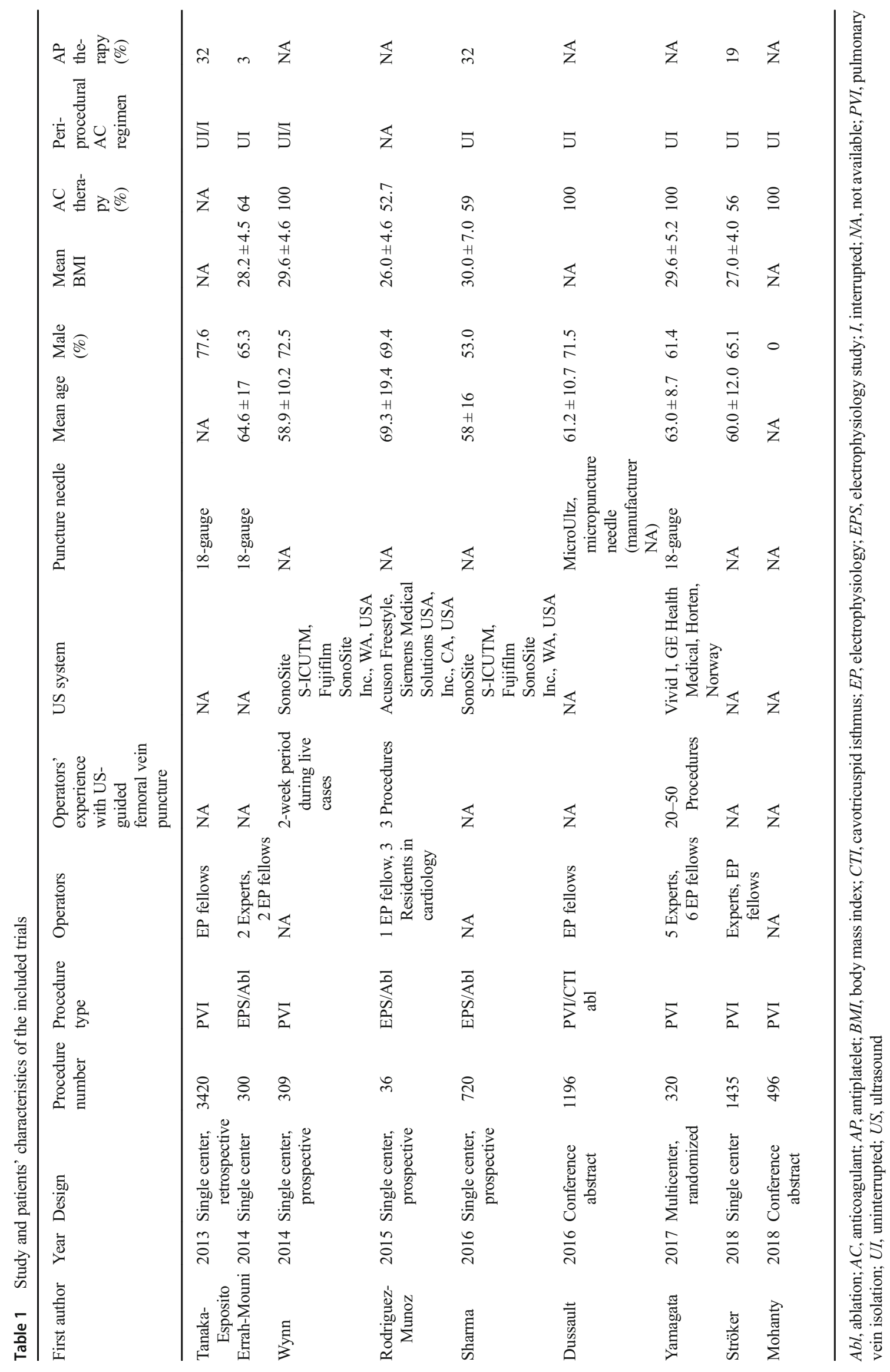


Academic Research Consortium (BARC) criteria (requiring nonsurgical, medical intervention by a health care professional; leading to hospitalization or increased level of care, or prompting evaluation) [14]. Secondary outcomes were minor vascular complications (groin hematomas $<$ BARC 2), inadvertent artery puncture, groin pain, and puncture time. Predefined subgroup analysis was conducted separately for patients undergoing pulmonary vein isolation (PVI) procedure. The review protocol was registered in the PROSPERO database under the registration number of CRD42019139143.

\section{Results}

Nine studies involving 8232 patients met our inclusion criteria, published between 2013 and 2018. One study was randomized and eight were observational, non-randomized (Table 1) [12, 15-22]. The results of the literature search are summarized in Fig. 2.

Compared with the standard technique, the use of US for femoral vein puncture significantly reduced the rate of major vascular complications from 2.01 to $0.71 \%$. Calculated from this, $71 \%$ of relative risk reduction $(\mathrm{RR}=0.39,95 \% \mathrm{CI}, 0.17$ $0.51, p<0.0001$, Fig. 3), the number needed to treat (NNT) was approximately 77 ; that is, the US-guided puncture has to be applied in 77 patients to avoid 1 major adverse event.

Risk of minor vascular complications with US guidance showed a reduction from 1.49 to $0.45 \%(R R=0.30,95 \%$ CI, $0.14-0.62, p=0.001$, Fig. 4). The risk of inadvertent arterial puncture was reduced from 19.7 to $5.93 \%(\mathrm{RR}=0.31$, 95\% CI, 0.17-0.58, $p=0.0003$ ) compared with the standard group (Fig. 4). The time required for the puncture was shorter (mean difference $=-92.1 \mathrm{~s}, 95 \% \mathrm{CI},-142.12--42.07 \mathrm{~s}$, $p=0.0003$, Fig. 4) and groin pain was less frequent (22.22 vs. $13.04 \%, \mathrm{RR}=0.41,95 \% \mathrm{CI}, 0.41-0.79, p=0.0008)$ in the US group (Fig. 4).
Subgroup analysis of patients undergoing PVI also showed significant reduction of major vascular complications (2.07 vs. $0.87 \%, \mathrm{RR}=0.27,95 \%$ CI, $0.12-0.64, p=0.003$, Fig. 5 ) and inadvertent artery puncture $(19.28$ vs. $6.52 \%, R R=0.29$, $95 \%$ CI, 0.17-0.50, $p=0.00001$, Fig. 4). Among patients undergoing catheter ablation for AF, the NNT was 83 . The evaluation of secondary outcomes in the subgroup analysis could not be performed due to the lack of data.

Based on the results of $\mathrm{Chi}^{2}$ and $\mathrm{I}^{2}$ tests, the sample proved to be homogenous and consistent, except for data regarding inadvertent arterial puncture, where moderate inconsistency could be detected. Funnel plot analyses showed no sign of possible publication bias.

\section{Discussion}

Our meta-analysis demonstrated that the use of US guidance for vascular access among patients undergoing EP procedures reduces the relative risk of major vascular complications by $71 \%$ compared with the standard, anatomical landmarkguided technique. In addition, US-guided femoral vein puncture significantly reduced puncture time and improved outcomes regarding minor vascular complications, inadvertent arterial puncture, and postprocedural groin pain. In the subgroup analysis of patients undergoing PVI, the rates of major vascular complications and inadvertent artery puncture were significantly lower in the US-guided group.

Procedures involving puncture of major vessels are increasingly used in various fields of medicine. This is a tendency that besides opening possible new treatment options, it also exposes patients to a certain risk for complications. Data from the American Society of Anesthesiologists Closed Claims Project database indicates that the majority of central venous catheter placement-associated complications are vascular injuries [23]. In a previous review, the overall complication rate
Fig. 2 Flowchart of study selection

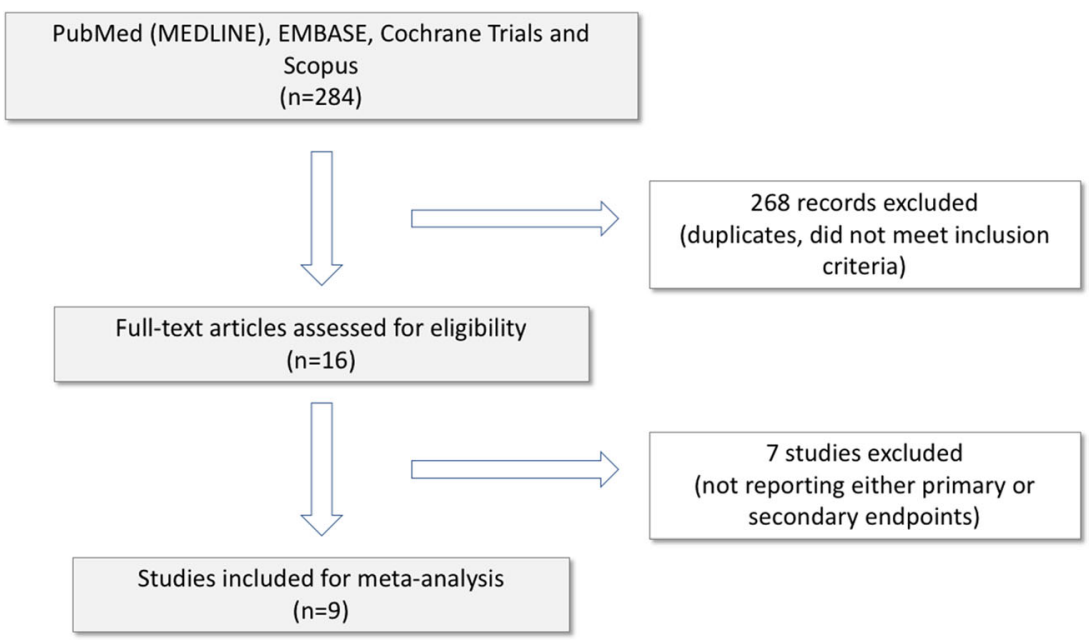




\begin{tabular}{|c|c|c|c|c|c|}
\hline \multirow[b]{2}{*}{ Study or Subgroup } & \multicolumn{2}{|c|}{ With ultrasound } & \multicolumn{2}{|c|}{ Without ultrasound } & \multirow[b]{2}{*}{ Weight } \\
\hline & Events & Total & Events & Total & \\
\hline Dussault & 1 & 439 & 10 & 757 & $6.8 \%$ \\
\hline Errahmouni & 0 & 150 & 4 & 150 & $3.5 \%$ \\
\hline Mohanty & 1 & 279 & 11 & 217 & $6.9 \%$ \\
\hline Sharma & 2 & 360 & 9 & 360 & $11.7 \%$ \\
\hline Ströker & 0 & 300 & 18 & 1135 & $3.8 \%$ \\
\hline Tanaka-Esposito & 2 & 1511 & 13 & 1909 & $12.2 \%$ \\
\hline mynn & 17 & 163 & 29 & 146 & $49.4 \%$ \\
\hline Yamagata & 1 & 159 & 3 & 160 & $5.7 \%$ \\
\hline Total $(95 \% \mathrm{CI})$ & & 3361 & & 4834 & $100.0 \%$ \\
\hline $\begin{array}{l}\text { Total events } \\
\text { Heterogeneity. Tau } \\
\text { Test for overall effe }\end{array}$ & $\begin{aligned} & 24 \\
0 & \mathrm{Chi}^{2} \\
= & 4.31(\mathrm{~F}\end{aligned}$ & $90, \mathrm{~d}$ & df $=7\left(P^{97}=\right.$ & $2=1$ & \\
\hline
\end{tabular}

Risk Ratio

Random, 95\% C

$0.17[0.02,1.34]$

$0.11[0.01,2.05]$

$0.07[0.01,0.54]$

$0.22[0.05,1.02]$

$0.10[0.01,1.69]$

$0.19[0.04,0.86]$

$0.53[0.30,0.92]$

$0.34[0.04,3.19]$

$0.29[0.17,0.51]$

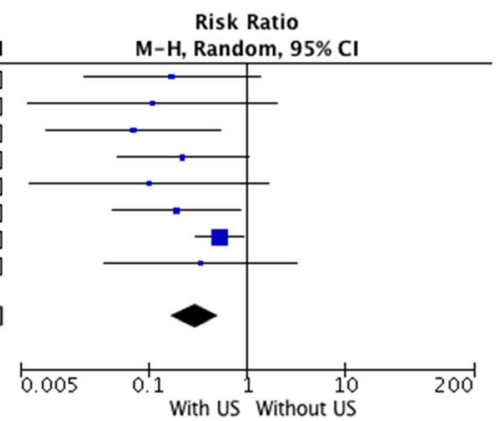

Fig. 3 Major vascular complications. US ultrasound

reached $15 \%$ for central venous catheterization [24]. This high frequency is partially related to the increasing rate of interventions requiring anticoagulant and antiplatelet medications, as well as to the limitations of the conventional palpation-based puncture technique.

The anatomical orientation points-guided puncture is considered to be the standard during femoral venous access, although examining bony landmarks and femoral arterial pulsation may not be sufficient for the localization of the femoral vein in a considerable proportion of cases. An analysis of the inguinal region computed tomographic scans showed that the femoral artery overlaps the femoral vein in two-thirds of the patients [25]. These individual variations may lead to unsuccessful puncture or various complications if direct visualization is not performed.

The US-guided approach allows direct visualization of femoral vessels with a higher rate of successful venous puncture. An analysis of four studies comparing the US-guided to the anatomical landmarks-guided technique for femoral vein cannulation showed that the use of US is associated with improved success rate, however, in these reports there were no significant differences in the complication rates, puncture time, arterial punctures, or hematomas [10]. Guidelines for the Prevention of Intravascular Catheter-Related Infections - developed by a task force comprising members from the Society of Critical
Care Medicine, the Society for Healthcare Epidemiology of America, and the American Society of Critical Care Anesthesiologists - recommended the use of US-guidance during central venous catheter insertions [26].

Electrophysiology procedures may represent a field where the safety aspects of the central venous access site are of paramount interest. The most common major complications of EP procedures are related to vascular access. These may require intervention and result in prolonged hospitalization [1, $27,28]$. The prevalence of these complications varies depending on the type of procedure. Vascular access-related complications have been described in $0.3-0.4 \%$ of supraventricular tachycardia ablations $[1,29]$, and $0.4-4.7 \%$ of premature ventricular complex/ventricular tachycardia ablations [1, 30, 31]. Patients undergoing AF ablation procedures experience a vascular access complication rate of $1-13 \%$ depending on the definition $[4,5,32,33]$.

Catheter ablation for AF not only has the most commonly performed ablation procedure but also has specific considerations regarding the vascular access complications [27, 34].

Besides the large-bore catheters and multiple access sites used for these procedures, in order to prevent ischemic complications, the recommended treatment comprises uninterrupted oral anticoagulant administration [35]. Oral and procedural anticoagulation may augment the importance and interfere

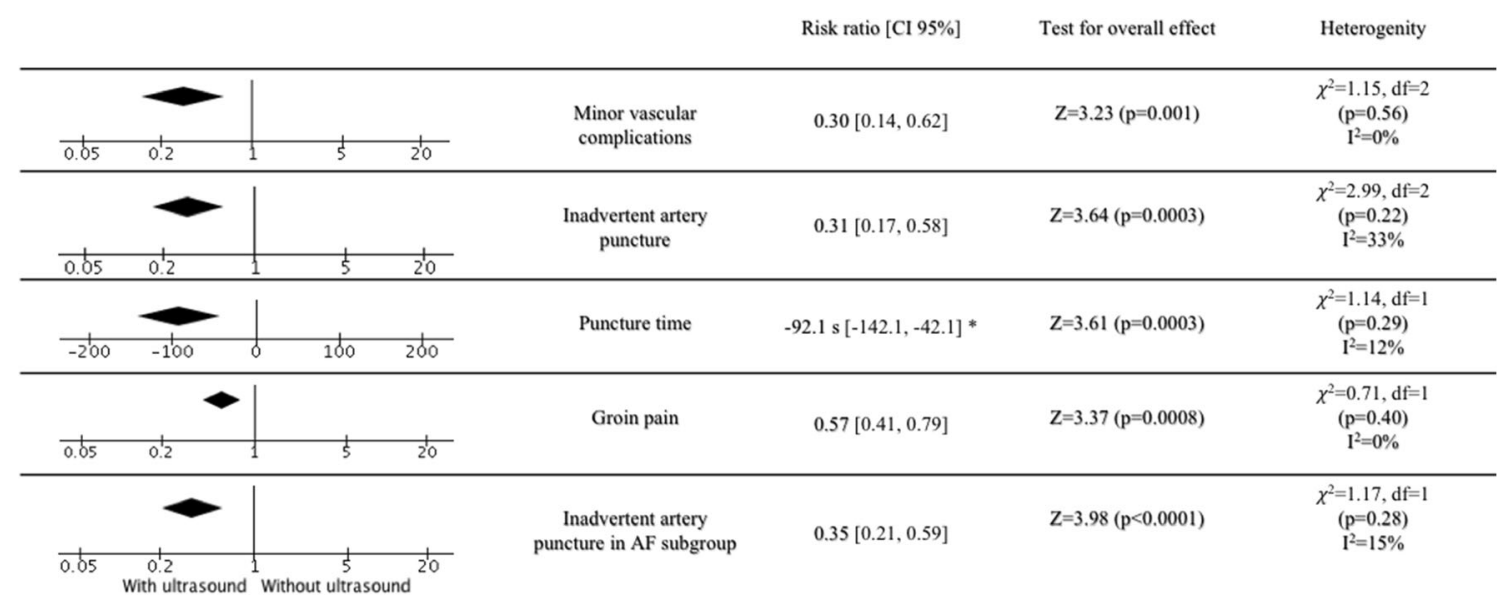

Fig. 4 Summary of outcomes of secondary endpoints. AF atrial fibrillation. *Mean difference (95\% CI) 


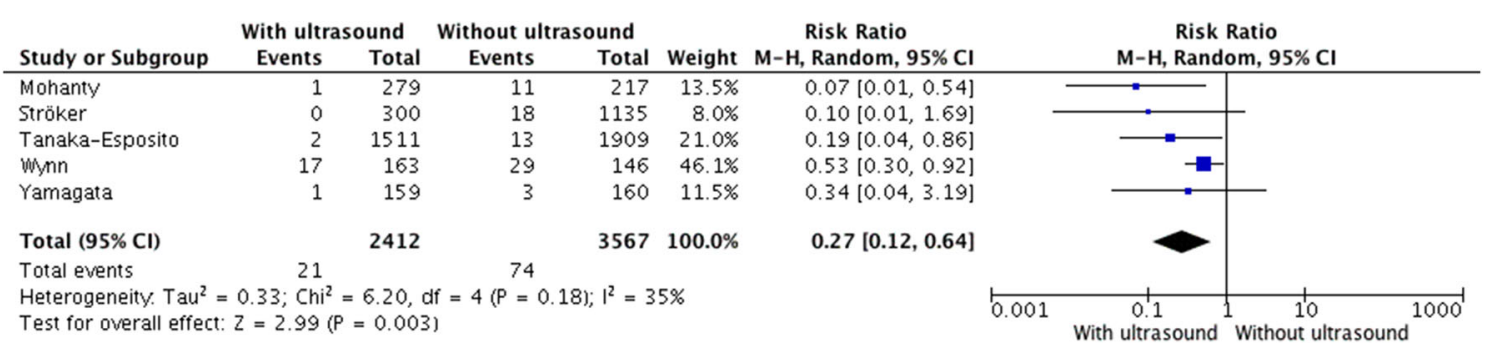

Fig. 5 Major vascular complications in the subgroup of patients undergoing pulmonary vein isolation

with the treatment of injuries suffered during the access and result in more frequent bleeding complications [27].

Improving the security of the catheter ablation remains a primary goal in electrophysiology. With a potential for easy adaptation in the EP laboratory environment, vascular US offers a quick and inexpensive technique with a steep learning curve. It does not increase the duration of the procedure, moreover-as our results showed-puncture time and thus the skin-to-skin measured procedure time can be reduced. For a detailed description of technical details, we refer to the review article of Wiles et al. describing the technique of USguided femoral vein puncture with special regards to its application in the EP laboratory [7, 36]. Despite the obvious benefits, the routine use of US for femoral vein access has not been widely adopted among the electrophysiologists.

In light of the fact that the number of EP procedures is increasing, prevention of vascular access-related complications is desirable not only to improve safety outcomes but also to reduce additional costs of the management of complications [37]. We found that the risk reduction achievable with the USassisted approach is reasonably high and the NNT to prevent major vascular complications is relatively low, supporting its routine use during femoral vein puncture for vascular access in EP procedures.

Our findings demonstrating benefits of the US guidance for EP procedures are in line with the results of a previous metaanalysis. Sobolev et al. performed an analysis of 4 trials including a total of 4605 patients comparing US-guided femoral vein cannulation in EP procedures to the anatomical landmark-based technique. The US-guided femoral vein puncture was associated with a $60 \%$ reduction of major vascular bleeding and a $66 \%$ reduction of minor vascular complications [11]. Since the publication of that analysis, several observational studies were published that were allowed to characterize the effect estimates with higher statistical power. Moreover, we could include data from the only randomized, controlled trial (RCT) in this field. In the multicenter, prospective ultrasound-guided femoral vein accessibility, safety and time (ULTRA-FAST) trial, 320 patients undergoing catheter ablation for AF were randomized to US-guided vs. conventional femoral vein puncture [12]. The use of US was associated with preferable intraprocedural outcomes; however, there was no difference in the major complication rates presumably due to the lower-than-expected complication rate in the conventional arm.

The present meta-analysis has some limitations to be acknowledged. Firstly, only one randomized study was included and the majority of data originate from observational studies. This may introduce potential biases and/or effects of unmeasured confounders. In general, observational studies are more precise but supposed to be more subject to bias. Importantly, we found very similar outcomes in the RCT compared with the observational studies. The lack of heterogeneity in this aspect supports the fact that the treatment effects of the USguided approach are similar, independent from trial design, and not affected by potential bias.

Important differences also may exist in patient demographics that might affect outcomes and are not accounted for in this analysis. Use of a random-effects model can help mitigate the potential effect of heterogeneity and the high level of significance supports the validity of the results. Secondly, secondary outcomes were not reported by all of the included studies limiting further analysis of potential mechanisms. Finally, data regarding the operators performing the puncture and especially data on operators' previous experience with US-guided technique were also insufficient despite the probable impact of a learning curve effect.

\section{Conclusion}

In conclusion, our meta-analysis including 8232 patients demonstrated that real-time US-guidance of femoral vein puncture in EP procedures is beneficial by reducing major and minor vascular complications, inadvertent artery puncture, postprocedural groin pain, and puncture time. These data may substantiate recommendations for the routine use of US in EP procedures.

Funding information Open access funding provided by University of Pécs (PTE). This work was supported by the GINOP-2.3.3-15-201600031 grant of the Hungarian Government.

\section{Compliance with ethical standards}

Conflict of interest The authors declare that they have no conflict of interest. 
Ethical approval The study was performed in accordance with the Declaration of Helsinki and was evaluated following institutional guidelines.

Open Access This article is licensed under a Creative Commons Attribution 4.0 International License, which permits use, sharing, adaptation, distribution and reproduction in any medium or format, as long as you give appropriate credit to the original author(s) and the source, provide a link to the Creative Commons licence, and indicate if changes were made. The images or other third party material in this article are included in the article's Creative Commons licence, unless indicated otherwise in a credit line to the material. If material is not included in the article's Creative Commons licence and your intended use is not permitted by statutory regulation or exceeds the permitted use, you will need to obtain permission directly from the copyright holder. To view a copy of this licence, visit http://creativecommons.org/licenses/by/4.0/.

\section{References}

1. Bohnen M, Stevenson WG, Tedrow UB, et al. Incidence and predictors of major complications from contemporary catheter ablation to treat cardiac arrhythmias. Heart Rhythm. 2011;8:1661-6. https:// doi.org/10.1016/j.hrthm.2011.05.017.

2. Hussain SK, Eddy MM, Moorman L, Malhotra R, Darby AE, Bilchick K, et al. Major complications and mortality within 30 days of an electrophysiological procedure at an academic medical center: implications for developing national standards. J Cardiovasc Electrophysiol. 2015;26:527-31. https://doi.org/10.1111/jce. 12639.

3. Spertus JA, Kettelkamp R, Vance C, Decker C, Jones PG, Rumsfeld JS, et al. Prevalence, predictors, and outcomes of premature discontinuation of thienopyridine therapy after drug-eluting stent placement: results from the PREMIER registry. Circulation. 2006;113: 2803-9. https://doi.org/10.1161/CIRCULATIONAHA.106. 618066.

4. Cappato R, Calkins H, Chen SA, et al. Updated worldwide survey on the methods, efficacy, and safety of catheter ablation for human atrial fibrillation. Circ Arrhythmia Electrophysiol. 2010;3:32-8. https://doi.org/10.1161/CIRCEP.109.859116.

5. Shah RU, Freeman JV, Shilane D, et al. Procedural complications, rehospitalizations, and repeat procedures after catheter ablation for atrial fibrillation. J Am Coll Cardiol. 2012;59:143-9. https://doi. org/10.1016/j.jacc.2011.08.068.

6. Steffel J, Verhamme P, Potpara TS, et al. The 2018 European heart rhythm association practical guide on the use of non-vitamin $\mathrm{K}$ antagonist oral anticoagulants in patients with atrial fibrillation: executive summary. Europace. 2018. https://doi.org/10.1093/ europace/euy054.

7. Wiles BM, Child N, Roberts PR. How to achieve ultrasound-guided femoral venous access: the new standard of care in the electrophysiology laboratory. J Interv Card Electrophysiol. 2017;49:3-9. https://doi.org/10.1007/s10840-017-0227-9.

8. Prabhu MV, Juneja D, Gopal PB, Sathyanarayanan M, Subhramanyam S, Gandhe S, et al. Ultrasound-guided femoral dialysis access placement: a single-center randomized trial. Clin J Am Soc Nephrol. 2010;5:235-9. https://doi.org/10.2215/CJN. 04920709 .

9. Powell JT, Mink JT, Nomura JT, et al. Ultrasound-guidance can reduce adverse events during femoral central venous cannulation. J Emerg Med. 2014;46:519-24. https://doi.org/10.1016/j. jemermed.2013.08.023.
10. Brass P, Hellmich M, Kolodziej L, et al (2015) Ultrasound guidance versus anatomical landmarks for subclavian or femoral vein catheterization. $1-83$.

11. Sobolev M, Shiloh AL, Di Biase L, Slovut DP. Ultrasound-guided cannulation of the femoral vein in electrophysiological procedures: a systematic review and meta-analysis. Europace. 2017;19:850-5. https://doi.org/10.1093/europace/euw113.

12. Yamagata K, Wichterle D, Roubíček T, et al. Ultrasound-guided versus conventional femoral venipuncture for catheter ablation of atrial fibrillation: a multicentre randomized efficacy and safety trial (ULTRA-FAST trial). Europace. 2018;20:1107-14. https://doi.org/ 10.1093/europace/eux 175.

13. Moher D, Shamseer L, Clarke M, et al. Preferred reporting items for systematic review and meta-analysis protocols (PRISMA-P) 2015 statement. 2015;4:1-9. https://doi.org/10.1186/2046-4053-4-1.

14. Mehran R, Rao SV, Bhatt DL, Gibson CM, Caixeta A, Eikelboom $\mathrm{J}$, et al. Standardized bleeding definitions for cardiovascular clinical trials: a consensus report from the bleeding academic research consortium. Circulation. 2011;123:2736-47. https://doi.org/10.1161/ CIRCULATIONAHA.110.009449.

15. Tanaka-Esposito CC, Chung MK, Abraham JM, Cantillon DJ, AbiSaleh B, Tchou PJ. Real-time ultrasound guidance reduces total and major vascular complications in patients undergoing pulmonary vein antral isolation on therapeutic warfarin. J Interv Card Electrophysiol. 2013;37:163-8. https://doi.org/10.1007/s10840013-9796-4

16. Errahmouni A, Bun SS, Latcu DG, Saoudi N. Ultrasound-guided venous puncture in electrophysiological procedures: a safe method, rapidly learned. PACE - Pacing Clin Electrophysiol. 2014;37: 1023-8. https://doi.org/10.1111/pace.12386.

17. Wynn G, Haq I, Hung J, et al. Improving safety in catheter ablation for atrial fibrillation: a prospective study of the use of ultrasound to guide vascular access. J Cardiovasc Electrophysiol. 2014;25:680 5. https://doi.org/10.1111/jce.12404.

18. Rodríguez Muñoz D, Franco Díez E, Moreno J, Lumia G, Carbonell San Román A, Segura de la Cal T, et al. Wireless ultrasound guidance for femoral venous cannulation in electrophysiology: impact on safety, efficacy, and procedural delay. PACE-Pacing Clin Electrophysiol. 2015;38:1058-65. https://doi.org/10.1111/ pace. 12670.

19. Sharma P, Padala S, Gunda S, Koneru JN, Ellenbogen KA. Vascular complications during catheter ablation of cardiac arrhythmias: a comparison between vascular ultrasound guided access and conventional vascular access. J Cardiovasc Electrophysiol. 2016;27: 1160-6. https://doi.org/10.1111/jce.13042.

20. Dussault C, Baldinger S, Tedrow UB, et al. Preventing vascular access complications for ablation on uninterrupted anticoagulation: impact of ultrasound guidance and micropuncture needle. Hear Rhythm. 2016;13:S427-514. https://doi.org/10.1016/j.hrthm. 2016.03.031.

21. Mohanty S, Trivedi C, Gianni C, et al. P5755Real-time ultrasound guidance for venous access reduces vascular complications in women aged 75 years or older undergoing catheter ablation for atrial fibrillation under uninterrupted anticoagulation. Eur heart $\mathrm{J}$. 2018;39. https://doi.org/10.1093/eurheartj/ehy566.p5755.

22. Ströker E, De Asmundis C, Kupics K, et al. Value of ultrasound for access guidance and detection of subclinical vascular complications in the setting of atrial fibrillation cryoballoon ablation. Europace. 2018;21:434-9. https://doi.org/10.1093/europace/euy154.

23. Domino KB, Bowdle TA, Posner KL, et al. Injuries and liability related to central vascular catheters. Surv Anesthesiol. 2005;49: 154-5. https://doi.org/10.1097/01.sa.0000165245.45492.1c.

24. McGee DC, Gould MK. Preventing complications of central venous catheterization. N Engl J Med. 2003;348:1123-33. https://doi. org/10.1056/NEJMra011883. 
25. Baum PA, Matsumoto AH, Teitelbaum GP, et al. Anatomic relationship between the common femoral artery and vein: CT evaluation and clinical significance. Radiology. 2014;173:775-7. https:// doi.org/10.1148/radiology.173.3.2813785.

26. O'Grady NP, Alexander M, Burns LA, et al. Guidelines for the Prevention of Intravascular Catheter-Related Infections. Clin Infect Dis. 2011;18:40-4. https://doi.org/10.1093/cid/cir257.

27. Cappato R, Ezekowitz MD, Klein AL, Camm AJ, Ma CS, le Heuzey JY, et al. Rivaroxaban vs. vitamin K antagonists for cardioversion in atrial fibrillation. Eur Heart J. 2014;35:3346-55. https:// doi.org/10.1093/eurheartj/ehu367.

28. Kirchhof P, Bax J, Blomstrom-Lundquist C, Calkins H, Camm AJ, Cappato R, et al. Early and comprehensive management of atrial fibrillation: Executive summary of the proceedings from the 2nd AFNET-EHRA consensus conference "research perspectives in AF”. Eur Heart J. 2009;30:2969-80. https://doi.org/10.1093/ eurheartj/ehp235.

29. Scheinman MM, Huang S. The 1998 NASPE prospective catheter ablation registry. PACE-Pacing Clin Electrophysiol. 2000;23: 1020-8. https://doi.org/10.1111/j.1540-8159.2000.tb00891.x.

30. Peichl P, Wichterle D, Pavlu L, et al. Complications of catheter ablation of ventricular tachycardia. Circ Arrhythmia Electrophysiol. 2014;7:684-90. https://doi.org/10.1161/circep.114. 001530.

31. Palaniswamy C, Kolte D, Harikrishnan P, et al. Catheter ablation of postinfarction ventricular tachycardia: ten-year trends in utilization, in-hospital complications, and in-hospital mortality in the United States. Hear Rhythm. 2014;11:2056-63. https://doi.org/10.1016/j. hrthm.2014.07.012.
32. Deshmukh A, Patel NJ, Pant S, Shah N, Chothani A, Mehta K, et al. In-hospital complications associated with catheter ablation of atrial fibrillation in the United States between 2104-2113. 2015. https:// doi.org/10.1161/CIRCULATIONAHA.113.003862.

33. Gupta A, Perera T, Ganesan A, et al. Complications of catheter ablation of atrial fibrillation a systematic review. Circ Arrhythmia Electrophysiol. 2013;6:1082-8. https://doi.org/10.1161/CIRCEP. 113.000768 .

34. Kneeland PP, Fang MC. Trends in Catheter Ablation for Atrial Fibrillation in the United States. J Hosp Med. 2010;5:379-90. https://doi.org/10.2217/FON.09.6.Dendritic.

35. Calkins H, Hindricks G, Cappato R, et al. 2017 HRS/EHRA/ ECAS/APHRS/SOLAECE expert consensus statement on catheter and surgical ablation of atrial fibrillation: executive summary. Europace. 2018;20:157-208. https://doi.org/10.1093/europace/ eux275.

36. Tanaka-Esposito CC, Tchou P. Ultrasound guided vascular access in the electrophysiology lab: should it be a standard of care? J Interv Card Electrophysiol. 2017;49:1-2. https://doi.org/10.1007/s10840017-0240-z.

37. Bode K, Ueberham L, Gawlik S, Hindricks G, Bollmann A. Inguinal vascular complications after ablation of atrial fibrillation: an economic impact assessment. Europace. 2019;21:91-8. https:// doi.org/10.1093/europace/euy132.

Publisher's note Springer Nature remains neutral with regard to jurisdictional claims in published maps and institutional affiliations. 